\title{
Safe Clavicle Fracture Surgery
}

\author{
S Venkatesh Babu
}

\begin{abstract}
a
The surgical treatment is being advocated for all types of displaced clavicle fractures currently. At the same time, the neurovascular and other serious operative complications are in rise. This article updates the applied anatomical knowledge and operative skills required for the orthopedic surgeon who intends to surgically fix the clavicle fracture safely.

Keywords: Clavicle, Complications, Fracture, Injury, Safe, Surgery, Trauma.

Journal of Orthopedics and Joint Surgery (2020): 10.5005/.jp-journals-10079-1026
\end{abstract}

\section{INTRODUCTION}

The aim of clavicle fracture treatment is to attain healthy bony union without any dysfunction, cosmetic deformity, or other morbidity. ${ }^{1}$ The incidence of fracture of the clavicle is $2.6-5 \%$ of all fractures in adults and $10-15 \%$ in children. ${ }^{2}$ The commonest site is the middle third of the clavicle. It expresses about $80 \%$ of all clavicle fractures and displaced in $73 \%$ of patients. ${ }^{3}$ The distal third fracture has $21-28 \%$ incidence with $10-52 \%$ are displaced ${ }^{4}$ and medial end contributes $2 \%$ of all clavicle fractures. ${ }^{5}$

A fall onto or a direct blow to the shoulder giving an axial compressive force on the clavicle is the most common mechanism of injury for clavicle fracture. ${ }^{6,7}$

The view on middle-third clavicle fracture treatment has changed in the last few years. Adult patients are presenting with high rate of nonunions than the earlier decade while being managed conservatively. ${ }^{8}$ Also, the outcome after treatment been measured with patient-reported outcome measures which detect even subtle loss of function in daily activities. ${ }^{9-11}$

Two major meta-analyzes of randomized clinical trials results concluded that surgical fixation yielded better efficacy than conservative treatment for displaced mid-third clavicle fractures from perspective of fracture healing and appearance. Presently, the plate osteosynthesis, intramedullary nails, Kirschner wires, and other systems being used for surgical management for displaced clavicular fractures. Also, the consensus regard to nonsurgical treatment for the midshaft clavicle fracture now is the fracture without displacement.,12 The operative treatment with a titanium elastic nail is claimed to be a safe, less invasive, and trustworthy treatment method for displaced uncomminuted midshaft clavicle fractures in adolescents. ${ }^{13}$

Considering the unstable nature of the lateral third clavicle fracture, the surgical treatment is justified by many surgeons at the moment with good functional outcome. , $^{44-17}$

Because of the rarity of medial clavicle fracture, the number of operative reports for this type of fracture is limited in the medical literature. However, few significant reports indicating the necessity of surgery in the medial third fractures rationally. Especially fractures in the skeletally immature patients, open medial third fractures with extensive soft tissue damage, neurovascular insult, and medial third fractures with sternoclavicular dislocation will need the surgical intervention. ${ }^{2,5,11,18-20}$
Department of Orthopaedics and Trauma Surgery, Sri Sakthi Hospital, Tirunelveli, Tamil Nadu, India

Corresponding Author: S Venkatesh Babu, Department of Orthopaedics and Trauma Surgery, Sri Sakthi Hospital, Tirunelveli, Tamil Nadu, India, Phone: +91 9843057118, e-mail: drsvbabu@hotmail.com How to cite this article: Babu SV. Safe Clavicle Fracture Surgery. J Orth Joint Surg 2020;2(2):62-65.

Source of support: Nil

Conflict of interest: None

In spite of the potential advantages in the clavicle fracture surgery, a quantity of major complications had been extensively reported by the surgeons in the recent decades. ${ }^{1-3,18,21-27}$

Poor knowledge of anatomy and inability to recognize key structures will lead to grave complications in surgery. ${ }^{28}$ The purpose of this review piece of writing is to rejuvenate the applied anatomical knowledge and required key operative skills for the surgeons who intend to surgically fix the clavicle fractures in a safe manner (Figs 1 and 2).

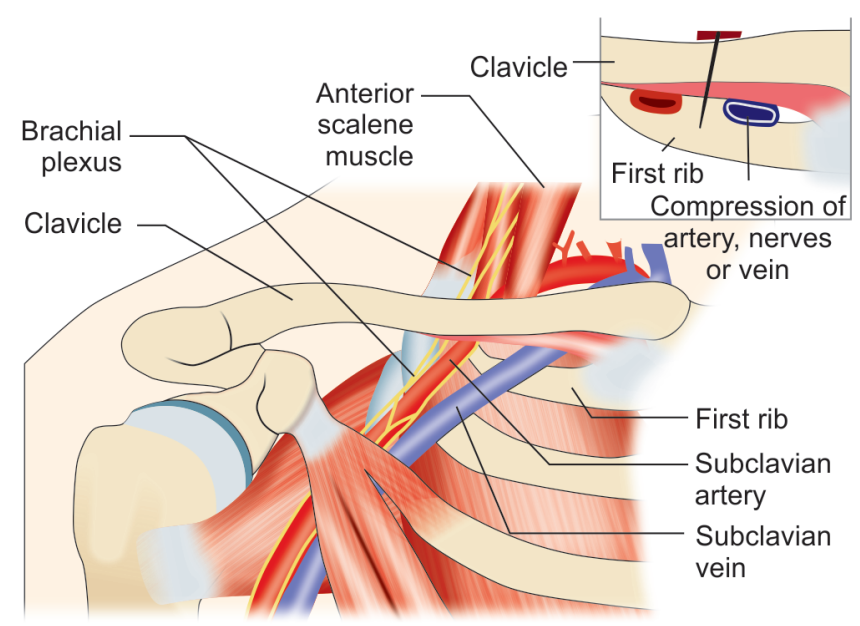

Fig. 1: Right clavicle with related vital structures

(0) The Author(s). 2020 Open Access This article is distributed under the terms of the Creative Commons Attribution 4.0 International License (https://creativecommons. org/licenses/by-nc/4.0/), which permits unrestricted use, distribution, and non-commercial reproduction in any medium, provided you give appropriate credit to the original author(s) and the source, provide a link to the Creative Commons license, and indicate if changes were made. The Creative Commons Public Domain Dedication waiver (http://creativecommons.org/publicdomain/zero/1.0/) applies to the data made available in this article, unless otherwise stated. 


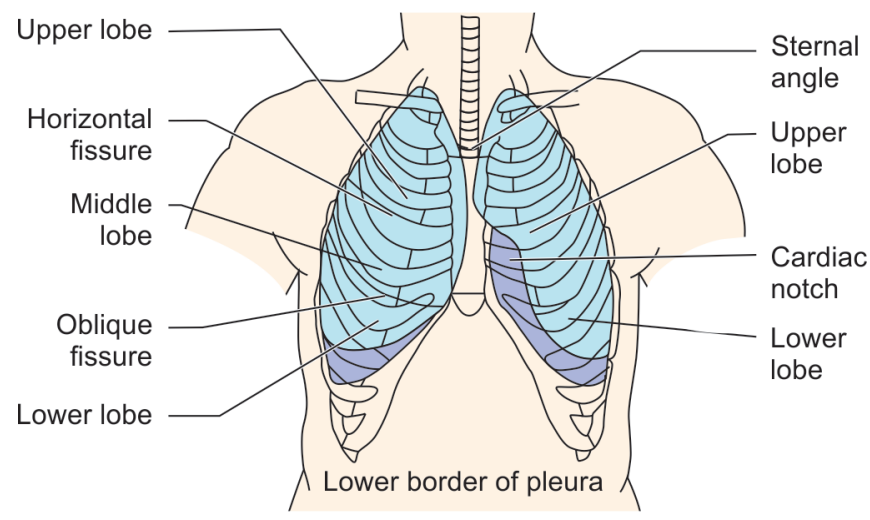

Fig. 2: Pleura extending to the supraclavicular space

\section{Applied Anatomy of the Clavicular Region $3,23,25$}

The uniquely twisted long bone, clavicle measures $13.5-14.5 \mathrm{~cm}$ in length and $17 \mathrm{~mm}$ in thickness having a "S" shaped cephaladcaudad curvature. The midshaft of the bone is thinnest and not stabilized by any ligaments and being relatively unprotected, thus making most fractures to occur here. The clavicle is also closer to significant vital structures like brachial plexus which is $20 \mathrm{~mm}$ from the bone and subclavian artery is $18 \mathrm{~mm}$ from the middle third of the clavicle. The subclavian vein lies just behind the medial clavicle. The pleura extend well up to the supraclavicular space in the process of inspiration. The exact clavicle length should be maintained for the good results. While performing the clavicular fracture surgery, the above factors need to be considered by the operating surgeon and his team.

Orthopedic surgeons had reported their intraoperative experience of fatal complications like vascular injuries, pneumothorax while operating on clavicle fracture. ${ }^{18,25}$

\section{Principles of Safe Clavicle Fracture Surgery $3,23,25,29$}

The operating surgeon must focus on the safety concern of the patient while treating the clavicle fracture surgically. The steps of the surgery, implants, and instrumentations going to be used, strategies for alternate operation, and potential complications must be communicated clearly and sometimes overly to all the team members is very important.

The following key factors will elucidate and support the surgeons in performing safe clavicle surgery.

- The preoperative planning and intimating the anesthesiologistThe expression of operative planning to the anesthesiologist regard to the surgery, other plans, and expected complications is of paramount importance. It will make their preparedness well in saving the patient in case of any emergency.

- Position of the patient-The beach chair position provides anterior and lateral access to the shoulder joint. The usage of image intensifier is much comfortable and posterior approach to the shoulder will be difficult. We should not use this position in medically compromised patients. The head must be in neutral position and close monitoring of the brain's perfusion pressure is needed in longer surgeries to avoid neurological, cardiac, and embolic phenomena.
- The supine position facilitates combined surgical approaches for a polytrauma patient but limited to anterior shoulder surgeries only.

- And regardless of the patient position chosen, the table set up must allow the anesthesiologist and surgical team to rapidly alter the position in the event of emergency.

- Incision for Clavicle Surgery should respect the Langer's Lines and not over the Clavicle. It should be just below the bone. ${ }^{30,31}$

- Surgical approaches-Anterior approach for anterior and superior claviclular plating with an oblique $8-10 \mathrm{~cm}$ incision.

- Nailing approach is by $1-2 \mathrm{~cm}$ incision made just lateral to the sternoclavicular joint anteriorly. Blunt dissection to bone is made to expose the entry point of the nail. Additional same size of incision is made just below the middle-third fracture site to open reduce in situations.

- Minimal invasive plate osteosynthesis (MIPO)-Anterior approach is used for diaphyseal clavicle fractures requiring anterior and superior plating. Two skin incisions, each 2-3 $\mathrm{cm}$ in length, are made over the lateral and medial ends of the clavicle corresponding in position to the ends of the preselected plate. A subcutaneous tunnel is created using blunt dissection connecting the medial and lateral incisions. Stab incisions are made for directly over the plate holes for insertion of screws, the same stab incisions are made for the pins and pointed reduction forceps.

- Superior approach to the clavicle can be used for all lateral, medial, and diaphyseal clavicle fractures with an oblique 8-10 $\mathrm{cm}$ incision is made just superiorly over the clavicle centered over the fracture site.

- Plane of the surgical exposure-The release of soft tissues must be gentle and subperiosteal. There are special instruments available today in protecting the vital structures during clavicle surgery.

- Drill, screw direction, and depth-Considering the thickness of clavicle which is $17 \mathrm{~mm}$, the screw length in the plate osteosynthesis should not be more than this.

For fixing the Medial third Clavicle Fracture-Drill/screws should be in superior-to-inferior direction.

For fixing the Middlethird Clavicle Fracture-Drill/screws should be in anterior-to-posterior direction.

Brief Notes on Specific Injuries in Clavicle Surgery and their Management ${ }^{3,8,18,23-25,32-36}$

\section{Subclavian Artery Injury}

Incidence: Rare.

Presentation: Life-threatening hemorrhage/palpable pulsatile mass/upper limb ischemia.

Level: First part of subclavian artery after medial/middle third of the clavicle fracture.

Management: Hypovolemia correction and addressing hemopneumothorax/CT angiography with repair of vessel—Finally fixation of fracture.

\section{Brachial Plexus Injury-Traction, Compression, and Entrapment}

Incidence: $1 \%$ of clavicle fractures. 
Presentation: Paresthesia/pain/posterior branches and middle branches involvement.

Level: Middle third of the clavicle fracture.

Management: MRI/recovery in few months_If not neurolysis/ nerve transfers.

\section{Pneumothorax and Hemothorax}

Incidence: 3\% from clavicle fractures.

Presentation: Associated scapular fracture/upper ribs fracture/ reported in open reduction and internal fixation (ORIF)/dyspnea and surgical emphysema.

Level: Middle third of the clavicle fracture.

Management: Intercostal drainage (ICD) and later fixation of fracture.

\section{Subclavian Vein Injury}

Incidence: Rare occurs during primary surgery or due to callus compression and our attempt to remove that!!

Presentation: Life-threatening as pulmonary embolism/vein thrombosis-Decrease in $\mathrm{SPO}_{2}$ and hypercapnia/negative intrathoracic pressure.

Level: Medial third of the clavicle fracture.

Management: Submerging the wound in normal saline/occlusive dressing/vascular expertise/careful removal of callus causing compression.

\section{Other Vessel Injuries}

Pseudoaneurysm: Presents as limb-threatening ischemia and treated with vascular graft or stent/excellent outcome.

Arteriovenous fistula: Presents as congestive heart failure/limb ischemia.

Venous Injury: Air embolism—Decrease in end-tidal $\mathrm{CO}_{2}$, decrease in $\mathrm{SPO}_{2}$ /aggressive fluid loading.

\section{Refracture}

Incidence: $4 \%$ following the removal of claviclular plate.

Level: Middle third of the clavicle fracture.

Management/Prevention: 12-18 months' retention of plate and avoid sports activity for 3 months after metal exit.

Risk Factors: Alcoholism and comminuted fractures and of course nonunion follows!!

\section{Thoracic Outlet syndrome}

Incidence: Rare-Can be vascular/neurogenic.

Presentation: Altered sensation/venous congestion/discoloration of the limb, compression at the costoclavicular space.

Mostly after conservative management of clavicle fractures (malunion)/few in ORIF cases.

Management: Excision of callus/resection of clavicle/corrective clavicle osteotomy/first rib resection/anterior and middle scalenectomy without rib resection.

\section{Discussion}

The clavicle is a special bone very closely related to neurovascular structures and thorax. The insult to these structures during surgery may lead to significant morbidity and mortality. Though the AO Principles of Fracture management advised the primary clavicle surgery in significantly displaced midshaft clavicle fracture ( $>20$ $\mathrm{mm})$, associated subclavian vessel injury, brachial plexus injury, ipsilateral scapular neck fracture, and painful nonunion of clavicle

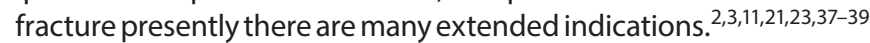

Currently, the clavicle fracture is being fixed with plate osteosynthesis, intramedullary fixation, and Kirschner wires mainly. The complications and functional outcome remain same for both the clavicle surgeries; however, the plate fixation has more neurovascular complications while compared to intramedullary nailing. ${ }^{36}$ There are plenty of surgeons had reported their neurovascular complications with plate osteosynthesis. The legendary Dr Neer himself had reported his vascular complications while operating on clavicle. . $3,18,21-27^{-27}$

Registration of adverse events following orthopedic surgery has a crucial role in patient safety and has received increasing attention today. The overall complication rate after orthopedic surgery is $12.7 \%$ in a well-established orthopedic center and implementation standard protocol will improve the safety and standard of care. ${ }^{27}$ The supervised residents in the teaching institution perform safe surgery to levels equal to those of senior orthopedic surgeons. It is established that the knowledge of applied anatomy of the operating region with expert skills will yield better results. $27,40,41$

\section{Conclusion}

Though the surgical treatment for all types of displaced clavicle fractures is justified today, the orthopedic surgeon must acknowledge the safety of the patient well during surgery. To evade the neurovascular and other serious complications, the applied anatomical knowledge and skills are essential for the surgeon while performing clavicle fracture surgery.

\section{Ethical Approval}

This article does not contain any studies with human participants or animals performed by any of the authors.

\section{References}

1. Qin $M$, Zhao S, Guo W, et al. Open reduction and plate fixation compared with non-surgical treatment for displaced midshaft clavicle fracture, a meta-analysis of randomized clinical trials, systematic review and meta analysis. Medicine 2019;98(20):1-9.

2. van der Meijden OA, Gaskill TR, Millett PJ. Treatment of clavicle fractures: Current concepts review. J Shoulder Elbow Surg 2012;21(3):423-429.

3. Hillen RJ, Burger BJ, Poll RG, et al. Malunion after midshaft clavicle fractures in adults, the current view on clavicular malunion in the literature. Orthopaedica 2010;81(3):273-279.

4. Sambandam B, Gupta R, Kumar S, et al. Fracture of distal end clavicle: a review. J Clin Orthopaed Trauma 2014;5:65-73.

5. Smelt J, Singh Khakha R, Harrison-Phipps K, et al. An isoloated traumatic medial third clavicular fracture requiring surgical fixation. Ann Thorac Surg 2017;103:297-298.

6. Stanley D, Trowbridge EA, Norris SH. The mechanism of clavicular fracture: a clinical and biomechanical analysis. J Bone Joint Surgery (Br) 1988;70:461-464.

7. Nowak J, Malimin H, Larsson S. The etiology and epidemiology of clavicular fractures a prospective study during a two year study in upsala, Sweden. Injury 2000;31:353-358.

8. Altamimi SA, McKee MD. Nonoperative treatment compared with plate fixation of displaced midshaft clavicular fractures, surgical technique. J Bone Joint Surg Am 2008;90(Suppl 2, Pt 1):1-8.

9. McKee MD, Pedersen EM, Jones C, et al. Deficits following nonoperative treatment of displaced midshaft clavicular fractures. J Bone Joint Surg Am 2006;88(1):35-40.

10. Pecci M, Kreher JB. Clavicle fractures. Am Fam Physician 2008;77(1): 65-70. 
11. Charles ER, Kumar V, Blacknall J, et al. A validation of the nottingham clavicle score: a clavicle, acromioclavicular joint and sternoclavicular joint-specific patient-reported outcome measure. J Shoulder Elbow Surg 2017;26(10):1732-1739.

12. Mckee RC, Whelan DB, Schemitsch EH. Mckee, operative versus nonoperative care of displaced midshaft clavicular fractures: a meta-analysis of randomized clinical trials. J Bone Joint Surg Am 2012;94(8):675-684.

13. Bithrey JW, Can der Merwe JF. Outcomes of treatment of displaced midshaft clavicle fractures in adolescents using titanium elastic nails. South Afr Orthopae J 2017;16(3):55-61.

14. Sajid S, Fawdington R, Sinha M. Locking plates for displaced fractures of the lateral end of clavicle potential pitfalls. Int J Shoulder Surge 2012;6(4):126-129.

15. Elgazar AS. Fixation of lateral clavicle fracture. AAMJ Al-Azhar Assiut Med J 2015;13(No 3):1-7.

16. Kapil-Mani KC, Acharya P, Arun S. Precontoured clavicular locking plate with broad lateral end: a newly designed plate for lateral third clavicle fractures. Malayas Orthopaed J 2018;12(1):15-20.

17. Ejagwulu FS, Lawal YZ, Maitama IM, et al. Management of clavicle fractures and adjacent clavicular joint dislocations in a tertiary health center, North West, Nigeria Nigerian. J Bas Clin Sci 2019;16(l):1-8

18. Skedros JG, Knight AN, Mears CS, et al. Temporary sternoclavicular plating for an unusual double clavicle fracture (medial nonunion, lateral clavicle) complicated by an intraoperative pneumothorax. Case Rep Orthopaed 2014;2014:206125.

19. Barrera-Ochoa $S$, Nunez JH, Domenech-Fernandez $P$, et al. Medial third clavicular fracture in combination with a posterior sternoclavicular dislocation in skeletally immature patients: 2 cases of a new proximal clavicular injury. JSES Open Access 2 2018. 97-99.

20. Frias M, Ramos R, Bernardes M, et al. Medial clavicle fracture dislocation surgically treated: case report. Trauma Cases and Reviews 2018;4(2):1-4.

21. Kitsis CK, Marino AJ, Krikler SJ, et al. Late complications following clavicular fractures and their operative management. Injury 2003;34(1):69-74.

22. Liu PC, Hsieh $\mathrm{CH}$, Chen $\mathrm{JC}$, et al. Infection after surgical reconstruction of a clavicle fracture using a reconstruction plate: a report of seven cases. Kaohsiung J Med Sci 2008;24(1):45-49.

23. Mouzopoulus G, Morakis E, Stamatakos M, et al. Complications associated with clavicular fracture. Orthop Nurs 2009;28(5):217-224.

24. Millett PJ, Hurst JasonM, Horan MarileeP, et al. Complications of clavicle fractures treated with intramedullary fixation. J Shoulder Elbow Surg 2011;20:86-91.
25. Clitherow HDS, Bain GI. Major neurovascular complications of clavicle fracture surgery. Shoulder Elbow 2015;7(1):3-12.

26. Pal CP, Dinkar KS, Shakunt RK, et al. Comparison of the functional outcome of intramedullary nailing versus plating in displaced midclavicular fractures. J Orthopaed Alli Sci 2018;6(1):13-16.

27. Willhuber GC, Stagnaro J, Petracchi M, et al. Short-term complication rate following orthopaedic surgery in a tertiary care center in Argentina. SICOT-J 2018;4(26):1-6.

28. Megrina JF, Wasson MN. Avoiding complications in endoscopic surgery. Contemp Ob Gyn 2018. 1-9.

29. AO Surgery Reference, 2019, https://www2.aofoundation.org/wps/ portal/surgery.

30. Der Tavitian J, Davidson JNS, Dias JJ. Clavicular fracture non-union surgical outcome and complications. Injury 2002;33(2):136-143.

31. Coupe BD, Wimhurst JA, Indar R, et al. A new approach for plate fixation of midshaft clavicular fractures. Injury 2005;36(10): $1166-1171$.

32. Smekal V, Deml C, Irenberger A, et al. Length determination in midshaft clavicle fractures: validation of measurement. J Orthop Trauma 2008;22(7):458-462.

33. Yoo MJ, Seo JB, Kim JP, et al. Surgical treatment of thoracic outlet syndrome secondary to clavicular malunion. Clin Orthopae Surg 2009;1:54-57.

34. Ishimaru $D$, Ogawa $H$, Sumi $H$, et al. Late thoracic outlet syndrome after clavicle fractures in patients with multiple trauma: a pitfall of conservative treatment. Open J Orthopaed 2012;2:90-93.

35. Beliaev AM, Fougere $C$. Thoracic outlet syndrome secondary to a mid-clavicle malunion. BMJ Case Rep 2015;2015:1-3.

36. Hussain N, Sermer C, Prusick PJ, et al. Intramedullary nailing versus plate fixation for the treatment displaced midshaft clavicular fractures: a systematic review and meta-analysis. Sci Rep 2016;6:34912.

37. Gille J, Schulz AP, Wallstabe $S$, et al. Hook plate for medial clavicle fracture. Indian J Orthop 2010;44(2):221-223.

38. Ruedi TP, Murphy WM, AO Principles of Fracture Management, 2000.

39. Kim W, Mckee MD. Management of acute clavicle fractures. Orthop Clin North Am 2008;39(4):491-505.

40. Minas V, Gul N, Aust T, et al. Urinary tract injuries in laparoscopic gynaecological surgery: prevention, recognition and management. Obstet Gynaecol 2014;16:19-28.

41. Theelen L, Bischoff C, Grimm B, et al. Current practice of orthopaedic surgical skills training raises performance of aupervised residents in total knee arthroplasty to levels equal to those of orthopaedic surgeons. Perspect Med Edu 2018;7:126-132. 